\title{
Die retoriek van godsdienstige politiek in Psalm 2
}

J H Coetzee

(RAU)

\section{ABSTRACT}

\section{The rhetoric of religious politics in Psalm 2}

The rhetorical argumentation strategies of Psalm 2 as a political-cultic poem are explored in order to highlight the function of these strategies, the exigency and the audience of the initial rhetorical situation. During the creation process of the psalm, the rhetor must have been influenced by the royal court or the king himself, reflecting aspects of the evolutionary process which the Zion theology went through. The rhetor's creation was to be implemented lively during the inauguration ceremony of the Judean king as rhetorical action during which the king (as new rhetor), the world rulers and nations (as universal audience), the Judean audience present at the political-cultic ceremony, as well as Yahweh were engaged in collaborative rhetorical action.

\section{INLEIDING}

Psalm 2 is een van die psalms van die Ou Testament waarin die wêrelde van politiek en godsdiens mekaar volledig ontmoet. Die psalm word gewoonlik onder die "koningspsalms" geklassifiseer wat tydens 'n inhuldigingseremonie van 'n Judese koning gebruik is. Hierdie studie het ten doel om 'n moontlike retoriese situasie van die psalm te rekonstrueer na aanleiding van die argumentasie wat die psalmdigter gebruik het. Hierbenewens word ook vanuit 'n polities-godsdienstige oogpunt vrae gevra oor dit wat moontlik tot die kulties-politieke retoriek in dié inhuldigingspsalm aanleiding gegee het. In wat hier volg word gepoog om moontlike antwoorde op die volgende vrae rondom Psalm 2 te kry:

a) Watter retoriese strategieë word deur die retor in die psalm gebruik?

b) Wat is die retoriese doel of funksie van die outeur met hierdie strategieë?

c) Wat is die behoefte of probleem van die retoriese situasie?

d) Watter moontlike oorspronklike retoriese situasie kan met behulp van die ondersoek gerekonstrueer word. 
Vir die doeleindes van hierdie studie word daar onderskei tussen tekskonvensies en retoriese strategieë1. Alhoewel hulle mekaar aanvul in die kommunikasie van die teks as geheel, is die primêre funksie van tekskonvensies en retoriese strategieë verskillend. Onder retoriese strategieë word hier verstaan wat Perelman en Olbrechts-Tyteca2 "rhetorical figures" in onderskeid van stylfigure noem. "Rhetorical figures" het 'n argumentatiewe funksie "if it brings about a change of perspective, and its use seems normal in relation to this new situation. If, on the other hand, the speech does not bring about the adherence of the hearer to this argumentative form, the figure will be considered an embellishment, a figure of style" 3 . 'n Stylfiguur kan dus 'n retoriese figuur word wanneer dit 'n argumentatiewe funksie verkry, anders het die stylfiguur net estetiese waarde met 'n spesifieke stilistiese effek. In hierdie studie word die aandag grootliks by die ondersoek van retoriese strategieë in Psalm 2 bepaal ${ }^{4}$.

Om die retoriese strategieë in Psalm 2 te identifiseer en hul funksie te kan aantoon, moet die psalm in sy geheel bestudeer word.

\subsection{Stanza 1 (1-6)}

Die vraag in chiastiese vorm waarmee die psalm begin is opvallend. As indirekte spreekhandeling ("speech act") doen hierdie vraag verslag van die optrede van die volke en nasies". Met hierdie "oop vraag"6 trek die retor nie net die gehoor se aandag nie ${ }^{7}$, maar dwing hy ook 'n antwoord af wat te doen het met die onmiddellike probleem ${ }^{8}$. Die retor en sy gehoor word dus met behulp van die vraag heel aan die begin reeds in 'n retoriese verhouding met mekaar geplaas. Die vraag word gestel om dit te artikuleer waaraan die retor in die psalm aandag wil gee, naamlik die behoefte/probleem van die retoriese situasie. Die gehoor sou aanvanklik moontlik soos volg in antwoord op die vraag kon reageer terwyl dit gevra word: Die volke en nasies is gedurig in politieke konflik met mekaar omdat dit maar deel van die wêreldpolitiek is. Maar die retor bou 'n waarde-oordeel oor die optrede van die volke in deur middel van die naamwoord $p$ ' (1). Hulle beplan verwaandheid, iets nietig, iets waardeloos. Duidelik word belaglikheid hier as argument gebruik ${ }^{9}$, wat dan ook in vers 4 met Jahwe se lag beantwoord word. Hierdie argument plaas die wêreldvolke onder verdenking, wat die gehoor kon laat wonder waaroor die vraag dan nou eintlik gaan. Die onmiddellike probleem (exigency) van die retoriese situasie word dan direk hierna in verse 2-3 toegelig. En dit is hierdie probleem wat met behulp van retoriese strategieë opgelos of verander moet word, 
naamlik: spanning tussen die nasies, volke, vorste, konings aan die een kant en Jahwe en sy gesalfde aan die ander kant. Die stel van hierdie probleem (1-3) en die oplossing van die probleem (10-12) omraam die res van die psalm (4-6; 7-9) wat eintlik die kern van die argumentasie uitmaak.

Die spanning word tussen die volke/konings en Jahwe/sy gesalfde bewerkstellig deur die voorsetsel לצ' (2). Die herhaling van in $2 \mathrm{~b}$ beklemtoon die feit dat hierdie spanning nie net tussen ?ְִּ en die nasies is nie, ook nie net tussen מִשִידו en die nasies nie, maar dit is 'n komplot van

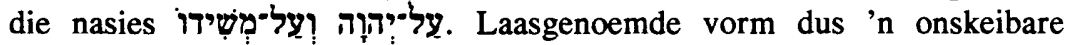
eenheid teen die vyandige nasies. Implisiet het ons hier met 'n argument van gesag te doen, aangesien die gesalfde aan Jahwe gekoppel word. Met betrekking tot Jahwe is dit ' $n$ duidelike positiewe beleefdheidstrategie waar die koning vir homself gemeenskaplike grond met Jahwe opeis ${ }^{10}$. Hierdie strategie word in verse 7-9 baie versterk. Dit hou egter negatiewe gevolge vir die volke en konings van die aarde in. Die hoogtepunt van die spanning, en van die antwoord op die vraag in vers 1 , kom in vers 3 na vore. Hier word woorde in die mond van die vyande deur die digter gelê: "Kom ons maak ons vry en gooi hulle juk af".

Die reaksie van Jahwe op die nasies en konings se agressie word in 4-6 gevind. Hierdie reaksie vertoon 'n parallelle patroon ten opsigte van 13.

* In 1 en 4 word die selfberaadslagende aktiwiteite van twee van die karakters aangetref, naamlik van die nasies en konings aan die een kant, en Jahwe aan die ander kant. Daar is onrus onder die aardse nasies en konings en hulle maak tevergeefse planne (1). Implisiet is hierdie planne primêr teen Jahwe gerig, maar sy gesalfde is ook betrokke (2). Daarteenoor lag Jahwe hulle in die hemel uit en spot met hulle (4). Die kontras tussen die volke van die aarde en Jahwe in die hemel vergroot die argument van belaglikheid dat die volke teen Jahwe en sy gesalfde opstaan.

* In 2 en 5 word vermeld van interaksie tussen die karakters. Eksplisiet word nou gesê die konings en leiers is in opstand teen Jahwe en teen sy gesalfde (2). Daarteenoor spreek Jahwe hulle in sy toorn aan en jaag hulle op loop (5). Die nasies en konings van die aarde is dus in konflik met Jahwe in die hemel.

* In 3 en 6 word die direkte rede van die karakters aangetref. Die konings en leiers sê: "Kom ons maak ons vry en gooi hulle juk af" (3). Daarteenoor sê Jahwe: "Dit is Ek wat hom as my koning gesalf het op Sion, my heilige berg" (6). Vir die aardse vorste gaan dit oor vrymaking van die oorheersing van Jahwe en sy gesalfde. Vir Jahwe in die hemel gaan 
dit oor die regeermag wat Hy aan sy gesalfde gee, maar nou "op Sion, my heilige berg", dit wil sê dit is aardse regeermag vanuit Sion geïnisieer deur Jahwe ${ }^{11}$. Implisiet gaan die konings en leiers se woorde oor die losmaak van die bande met Jahwe en sy gesalfde, terwyl Jahwe se woorde gaan oor die binding van die konings en leiers met Hom en sy gesalfde.

Aan die begin van 6 word klem op Jahwe gelê deur die voornaamwoord וָרִ Hierdie klem en die feit dat Jahwe ook self praat (woorde word in sy mond gelê), is baie duidelik 'n argument vanuit gesag. Die daad van salwing van die koning deur Jahwe hou dus verband met en vorm die inhoud van sy spot en toorn wat teen die nasies en konings van die aarde gerig is.

\subsection{Stanza 2 (7-9)}

Hier word 'n verslag deur die koning as "verteller" aangetref oor wat Jahwe met betrekking tot hom as koning aangekondig het. Die begrip (7a) is 'n politieke begrip in die sin van 'n dekreet wat uitgevaardig word. Kraus ${ }^{12}$ wys daarop dat die begrip $p \pi$ in die Ou Testament en spesifiek hier in Psalm 2:7, op "Königsprotokoll" (vaste prosedure in dokumentêre vorm) dui. Ook hierdie woorde wat in die mond van Jahwe gelê word is 'n argument vanuit gesag vanuit die oogpunt van die koning gesien. 'n Baie intieme relasie word deur Jahwe se dekreet tussen Hom en sy gesalfde daargestel, naamlik dié van Vader en seun. Die retor gebruik hier "ingroup identity markers" (seun en vader) as positiewe beleefdheidstrategie om gemeenskaplike grond tussen Jahwe en die koning te bewerkstelligis. 'n Resiproke (wederkerige) verhouding tussen seun en Vader word so geskep. Deur middel van die direkte rede van Jahwe (woorde wat in 6-9 in Jahwe se mond gelê word) manipuleer die retor die argumentasie so dat dit Jahwe is wat gemeenskaplike grond tussen Homself en die koning daarstel. Dit is dus 'n positiewe beleefdheidstrategie met Jahwe as subjek en die koning as objek. As gevolg hiervan kan die koning "goed voel" omdat hy met Jahwe geassosieer kan word. Hy word sodoende bemagtig.

Die resiproke funksie van hierdie strategie geld soos volg: Wanneer die koning tydens die retoriese situasie hierdie woorde ("Ek wil vertel wat die Here aangekondig het" - vers 7) sou uitspreek, dan is dit eintlik 'n erkenning of belydenis van "Ek behoort aan U". Dit sou dan ook kan dien as positiewe beleefdheidstrategie van die kant van die koning teenoor Jahwe. Die doel hiervan sou dan tydens die retoriese situasie wees dat die koning gemeenskaplike grond met Jahwe opeis. Teenoor die vyandige volke en regeerders sou dit onmiddellik die effek van 'n bedreiging inhou. Hierdie bedreiging teenoor die vyandige nasies word veral sterk in die 
argumente van die gee van die volke as eiendom van die koning (8) en die oorheersing van die volke deur militêre mag (9) verder geargumenteer. Die

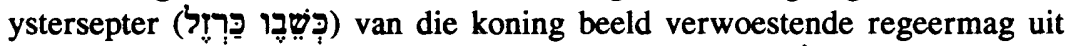

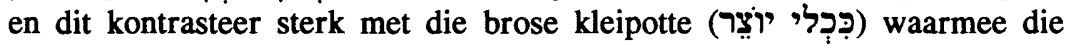
konings en vorste vergelyk word (9). Hierdie kontras is 'n voortsetting of versterking van die argument van belaglikheid of spot teen die vyande van Jahwe en sy gesalfde.

Ten opsigte van die Judese koning kan daar van sakrale koningskap gepraat word waarin die onderskeid tussen Jahwe en die menslike koning nie opgehef word nie ${ }^{14}$. Vanuit hierdie sosiaal-teologiese relasie het die seun/gesalfde die reg om van sy Vader dinge te vra. Die belofte van Jahwe dat die seun mag vra en $\mathrm{Hy}$ sal voorsien is ook 'n positiewe beleefdheidstrategie waardeur Jahwe sy samewerking aan die koning beloof 15 . Hierdie strategie word deur die retor gebruik tot voordeel van die Judese koning en tot nadeel van die nasies en konings van die aarde. Die koning beleef ook dit as bemagtiging deur Jahwe. Binne die konteks van die vyandskap tussen die volke en Jahwe en sy gesalfde word die volke en die hele aarde aan die seun/gesalfde gegee met die doel dat hulle verpletter moet word. Die retor stel die Judese koning dus hier as die ideale navolgenswaardige model voor wat die kultiese gehoor moet inspireer, terwyl die konings van die aarde die anti-model is wat nie navolgenswaardig optree nie ${ }^{16}$.

\subsection{Stanza 3 (10-12)}

Die hele derde stanza is eintlik 'n argument vanuit gesag omdat dit gegrond is op die gesagsfiguur van Jahwe wat gedien moet word. Op grond van die gesag wat die gesalfde van Jahwe ontvang het, stel hy die konings en regeerders van die aarde in 11-12 direk vermandend voor 'n ultimatum in die vorm van 'n dreigement. Hulle moet Jahwe met ontsag dien ${ }^{17}$ en Hom nie kwaad maak nie, anders sal hulle omkom. Die vyande word gedreig met Jahwe se toorn wat vinnig opvlam (12). Ten opsigte van die vyande is dit vanuit die Judese koning se oogpunt 'n negatiewe beleefdheidstrategie 18 wat direk aan die konings en regeerders gerig word. Die direkte negatiewe beleefdheidstrategieë (negative politeness bald-on-record) ${ }^{19}$ het hier ten doel om reguit in die gesig van die volke en konings van die wêreld te sê dat hulle Jahwe moet dien, dan sal hulle daarby baat. Dit is dus 'n ontsnappingsroete wat die koning vir die volke aanbied sodat hulle kan "save face", of om vir hulle te sê dat daar belangriker dinge in die lewe is

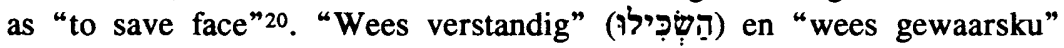
(ר) (T) word in 10 parallel gebruik. Dit beteken dat verstandigheid en bereidwilligheid om gewaarsku te word hier sterk met mekaar verband hou 
en dat die volke en konings eintlik onverstandig optree. Die inhoud van die ultimatum behels dat die volke en konings Jahwe met vreugde moet dien, anders kom sy toorn oor hulle (11-12). Sulke verstandige optrede loop uit op seën of geluk (12b). Die retor wil dus die aanvanklike optrede van die vyandige konings en volke omkeer na gehoorsaamheid aan Jahwe en sy gesalfde.

\section{DIE GEHOOR EN RETORIESE SITUASIE}

Beide die vraag (1) en die antwoord op die vraag (2-3) betrek die universele gehoor ${ }^{21}$ by die retoriese situasie: volke, nasies, konings en vorste. Hulle verteenwoordig hier die hele politieke Umwelt wat moontlik 'n bedreiging vir Israel kan wees. Deur die vermelding van מִשִׁיחור word die retoriese situasie ook polities-kulties bepaal. Dit betrek die kultiese gemeenskap van Juda by die retoriese situasie as deel van die gehoor. En uiteindelik word Jahwe ook by die gehoor betrek omdat hierdie psalm binne die kultus ook 'n “gebed" word ${ }^{22}$. Jahwe word as deel van die gehoor betrek op 'n baie interessante wyse. Hy word deur die retor gebruik om argumente vanuit gesag te implementeer, maar ook om aan Hom deur middel van positiewe beleefdheidstrategieë die "boodskap" oor te dra dat die koning en die volk van Juda aan Hom verbind wil wees. Laasgenoemde gedagte is implisiet in die retoriek van die psalm ingebou met behulp van die Sionsteologie ${ }^{23}$. Benson ${ }^{24}$ sê tereg dat sprekers en skrywers, terwyl hulle retories optree, nie slegs hulself skep nie, maar hulle skep ook hul gehore. "That creation is an act of rhetorical being and an invitation to rhetorical being". Die gehoor word dus geskep om aktief betrokke te wees binne die retoriese situasie.

Dit is hoogs waarskynlik dat Psalm 2 uit die vóór-eksiliese Judese koningskapstyd dateer ${ }^{25}$. Kraus ${ }^{26}$ maak 'n sterk saak daarvoor uit dat die Sitz im Leben van die psalm in die troonsbestygingsfees (eenmalig of jaarliks) van die Judese konings lê. Indien ons egter die retoriese situasie wil rekonstrueer, is dit belangrik om daarop te let dat die retoriese situasie en die historiese situasie nie dieselfde is nie. In navolging van Brinton is Vorster ${ }^{27}$ tereg van mening dat daar 'n noue verband tussen die retor se "belangstelling" en die "behoefte" van die situasie bestaan. Die retoriese situasie ontstaan wanneer die "behoefte" van die situasie in relasie tot die "belangstelling" van die retor kom. Die retor werk met basiese feite, maar skep 'n behoefte vanuit die historiese situasie op grond van 'n sekere belangstelling van hom. So word 'n retoriese situasie wat met die historiese situasie verband hou gebore. 
Ter illustrasie van die ontwikkelingsproses van 'n retoriese situasie word 'n voorbeeld uit die Amerikaanse geskiedenis geneem. Medhurst ${ }^{28}$ het die interaksie tussen politiek en godsdiens tydens 'n bepaalde situasie in die geskiedenis van die Verenigde State van Amerika bestudeer. Hy toon aan hoedat daar in 1965 voorbereidings getref is vir die daarstel van 'n gebed wat tydens die inhuldiging van die Amerikaanse president, Lyndon Baines Johnson, in die openbaar gebid moes word. Johnson het gereël dat verskillende aangewese geestelikes vooraf gebede indien. Met die hulp van sy toespraakpersoneel het hy voorstelle vir weglatings en toevoegings tot die gebede gemaak. Hy het ook finale goedkeuring verleen aan 'n bepaalde gebed om gebid te kon word ${ }^{29}$. Gebede het dus hier in opdrag van die president ontstaan vir gebruik tydens sy inhuldigingseremonie. Dit het duidelik die moontlikheid van strategiese voordele vir die president en moontlik die land ingehou om spesifieke geestelikes uit die diverse bevolking te versoek om gebede daar te stel. Medhurst toon aan hoedat daar selfs stryd tussen verskillende geestelike groepe ontstaan het om by hierdie saak betrokke te kon wees. Van die finale "produk" sê Medhurst:

"The importance of Davis's prayer is not in the rhetoric per se, but in the contextual, processual, and correlational features that called it into being, shaped it, and modified it in line with existing exigencies. Study of the prayer is important because it helps to unmask the forces operating in the processes of invention, arrangement, style, and delivery" 30 .

Belangrik is die pragmatiese en funksionele doelwitte wat gebed tydens die inwyding van die president gehad het:

"For inaugural planners and political strategists (my kursivering), prayer functioned rhetorically to identify the incoming leader with goodness and righteousness. It was an explicit sign that the president believed in God, prayer, and institutionalized religion. It was an implicit testimony to the rapprochement that occurred between civil and religious authorities shortly after the official separation of church and state. It was, in short, good politics.

For the clergymen (my kursivering) who participated in events of state, prayers functioned to remind the civil authorities of their exercise of power under God. Participation was a way of redeeming, if only symbolically, the power and prestige that once accompanied high ecclesiastical office. Though personal power was often highly circumscribed, clerical participation functioned to remind the audience (my kursivering), both political and lay, of the institutional importance of organized religion. 
For the audience members (my kursivering) the prayers functioned as rhetorical legitimators of American myths of state, of uncontested propositions to which Americans had traditionally paid obeisance: that the leader was blessed by God; that American ideals were lofty and unblemished; that Americans were God's people; that America had a responsibility to provide moral leadership to the world. These were propositions to be honored and remembered, not debated, for such is the nature of epideictic discourse" 31 .

Daar is waarskynlik geen direkte afleidings te maak uit die ontstaan van Davis se gebed in die Amerikaanse geskiedenis wanneer ons 'n psalm soos Psalm 2 ondersoek nie. Psalm 2 is immers ook nie 'n tipiese gebed wat tot God gerig word nie. Dit is eerder 'n epideiktiese vermaning gegrond op 'n profetiese dekreet wat aangaande die verhouding tussen die koning en Jahwe uitgevaardig is. En tog laat Psalm 2 'n mens met vrae rondom die ontstaansituasie, die retoriese situasie en die pragmatiese en funksionele doelwitte wat baie sterk verband hou met bogenoemde situasie uit die moderne geskiedenis.

'n Moontlike retoriese situasie van Psalm 2 sou aan die hand van al bogenoemde gegewens gerekonstrueer kon word met Bitzer ${ }^{32}$ se definisie van 'n retoriese situasie as vertrekpunt:

"Rhetorical situation may be defined as a complex of persons, events, objects, and relations presenting an actual or potential exigence which can be completely or partially removed if discourse, introduced into the situation, can so constrain human decision or action as to bring about the significant modification of the exigence".

Die digter/retor was waarskynlik 'n personeellid van die tempel in Jerusalem, moontlik 'n priester. Kraus ${ }^{33}$ sien hom as iemand wat profeties geïnspireer was en wat betrokke was by die kultiese aktiwiteit van die troonsbestyging van die koning. Deur middel van die psalm skep die retor interaksie tussen woord en ritueel binne die kultus ${ }^{34}$. By die inhuldigingseremonie van die Judese konings of by die jaarlikse koninklike Sionsfees ${ }^{35}$ vind daar verskeie rituele in die heiligdom asook in die paleis plaas ${ }^{36}$. Een daarvan is wat Kraus beskryf as "Per adoptionem wird der Regent durch einen prophetisch deklarierten Rechtsakt zum Sohn Gottes erklärt" ${ }^{37}$. Dit vind in die heiligdom plaas. Nadat hierdie aannemingsdekreet aangekondig is, moet die koning daarop antwoord. Dit is waarskynlik vir hierdie besondere oomblik wat Psalm 2 geskep is ${ }^{38}$. Die psalm is dus "a carefully prescribed act" 39 waarby die aangewese koning of die koningshuis moont- 
lik self ' $n$ inset kon gelewer het. Die sterk politieke klem wat hierdie psalm dra, sluit dus nie die aangewese koning se eie invloed by die totstandbrenging van die psalm uit nie.

Die retor skep vir hierdie antwoordsituasie van die koning 'n spesifieke "behoefte" of probleem, naamlik die bedreiging van die vyandige nasies en heersers teenoor Jahwe en sy gesalfde, wat opgelos moet word deur argumentasie. Binne die konteks van so 'n seremonie, pas so 'n "behoefte" of probleem baie goed in ${ }^{40}$. Hierdie motief van oorwinning van die koning oor sy vyande of die beskerming van die koning van sy vyande kom ook in ander koningspsalms voor ${ }^{41}$. Dit is duidelik dat die rede waarom die digter/retor hierdie probleem, en dus die retoriese situasie skep, in die kulties-politieke sfeer val en dit dus deel van die ontwikkeling van die Sionsteologie ${ }^{42}$ van Juda vorm. Sion as kultusplek was die plek waar Jahwe se oorlogsmag en sy almag geproklameer is en indrukwekkend aan die volk voorgehou is. Ook is die wêreldheerskappy van die koning net vanuit die skeppings- en wêreldheerskappy van Jahwe te verstaan ${ }^{43}$. Dit neem egter nie die werklikheid van historiese vyande waarmee die koning te doen kry, weg nie.

Die retoriese situasie is deur die retor gegenereer om die koning kragdadiglik te ondersteun in sy godsdienstig-politieke taak as "seun van God", wat te midde van 'n vyandige wêreld moet regeer. Nel${ }^{44}$ is reg wanneer hy sê dat die koningspsalms se "primary concern is to afford legitimacy to the Davidic dynasty and its ruling monarch in a comprehensive relationship with Yahweh, who has previously been recognised as a God of deliverance and not as a national God". Die psalmdigter is besig om te help skep en vorm aan die koningsbeskouing van $\mathrm{Juda}^{45}$. Hier lê dus ook iets van magsvertoon in opgesluit. Die koning word as 't ware op die wêreldkaart geplaas as die sterkste wêreldheerser omdat Jahwe hom aangestel het. Dit is waarom die retor argumente vanuit gesag gebruik in sy argumentering. Maar uit die aard van die situasie is dit nie magsvertoon van die koning ter wille van homself nie. Vanuit die kulties-politieke konteks van Juda moet die politieke wêreld rondom kennis neem en oortuig word daarvan dat die Judese koning nie alleen staan of net ter wille van homself daar is nie. Die universele gehoor, wat direk aangespreek word, moet weet dat die God van Israel die koning self aangestel het! Die kultiese gehoor word op hierdie wyse bemoedig en kry dus 'n unieke karakter van volk van God tussen die nasies.

Deur hier oor Jahwe te praat en woorde in die mond van Jahwe te lê, verraai die digter/retor iets van sy eie godsbeskouing en ook iets van sy eie karakter as aanhanger en ontwikkelaar van die Sionsteologie ${ }^{46}$. Deur 
die uitspreek van die psalm sê die retor by monde van die koning dat Jahwe die wêreldheerser, die God van die hemel is wat vanuit Sion die wêreld regeer. Hy bemagtig sy gesalfde. Alle volke en heersers moet by Hom skuiling soek, anders kom hulle om. Die retor ondersteun en bevorder die "staatsteologie".

\section{GEVOLGTREKKING}

Die psalmdigter maak veral van argumente vanuit gesag gebruik in Psalm 2 om sy gehoor (universeel en plaaslik) daarvan te oortuig dat die koning van Juda as ideaalkoning, sy gesag van Jahwe self ontvang. Om sy doel te bereik maak die retor van verskeie positiewe beleefdheidstrategieë gebruik waarmee hy vanuit die resiproke verhouding tussen Jahwe en die koning argumenteer. Hierdie strategieë het aanvanklik negatiewe gevolge vir die wêreldvolke en konings. Uiteindelik blyk dit egter duidelik dat die retor ook vir hulle goeie bedoelings het, wanneer hy deur middel van 'n direkte negatiewe beleefdheidstrategie die heil van die vyandige volke en heersers bepleit.

Die skep van 'n spesifieke retoriese situasie en die ontwikkeling van die argumentasie binne die retoriese situasie mak deel uit van die ontwikkeling van Juda se konings- en godsbeskouings binne die toe-nog-ontwikkelende-denkraamwerk van die Sionsteologie. Die retoriese situasie het ontwikkel uit die historiese situasie van die inhuldigingseremonie van 'n Judese koning en die problematiek van die politieke bedreiging van die omringende nasies en heersers. Die retor het waarskynlik in opdrag van die koningshuis die psalm vir gebruik binne die polities-kultiese sfeer geskep. Die psalm is geskep met die oog op 'n lewendige retoriese situasie tydens die inhuldigingseremonie van die koning. Tydens daardie retoriese situasie tree die koning, die universele gehoor, die lokale gehoor en Jahwe in 'n gesamentlike retoriese spraakhandeling. Legitimering van die internasionale staanplek van die Judese koning op grond van Jahwe se aanneming van hom as seun vorm die kern van die argumente, terwyl dit die grondslag van die heil van die vyandige nasies en heersers vorm.

\section{NOTAS:}

1 J H Potgieter, A Semitic Perspective on Old Testament Studies, OTE (Special edition) $7 / 4$ (1994), 319. Vergelyk ook G T M Prinsloo, Polarity as dominant textual strategy in Psalm 8, OTE 8 (1995), 370-387 vir die gebruik van die term "textual strategy".

2 C H Perelman \& L Olbrechts-Tyteca, The New Rhetoric. A Treatise on Argumentation, London 1969, 167-179. 
3 Perelman \& Olbrechts-Tyteca, $a w, 169$.

4 E Wendland, Introit "into the sanctuary of God" (Psalm 73:17): Entering the theological "heart" of the psalm at the centre of the Psalter, OTE 11/1 (1998), 143-144 onderskryf die uitgangspunt hier dat 'n psalm 'n oorredende doel kan hê.

5 Vergelyk E N Goody, "Towards a theory of questions", in: E N Goody (ed), Questions and politeness. Strategies in social interaction, London / New York / Melbourne 1978, 19 vir die rapporteringsfunksie en bevelsfunksie van vraagstelling as indirekte spreekhandeling.

6 "Oop vrae" is "incomplete propositions, for which the answer provides the missing clause", aldus Goody, $a w, 22$.

7 Die chiastiese vorm waarin die vraag gestel word, komplementeer die funksie van aandag trek. Vergelyk W G E Watson, Classical Hebrew Poetry. A Guide to its Techniques, Sheffield 1986, 205-206 vir die funksie van chiasmes.

8 Hierdie is volgens Goody, $a w, 52$ die twee basiese funksies van vraagstelling.

9 Perelman \& Olbrechts-Tyteca, $a$ w, 205-208.

10 Vergelyk $\mathbf{P}$ Brown \& $\mathbf{S}$ Levinson, "Universals in language usage: Politeness phenomena", in: E N Goody (ed), Questions and politeness. Strategies in social interaction, London / New York / Melbourne 1978, 108.

11 Tipiese tempelteologie word hier aangetref wanneer daar vermeld word dat Jahwe "in die hemel woon" (4) en dat Hy sy koning gesalf het "op Sion, my heilige berg". Op dialektiese wyse word die verbintenis tussen hemel en aarde voorgestel sonder om die een met die ander te identifiseer of om hulle van mekaar af te grens. Vergelyk H Spieckermann, Heilsgegenwart. Eine Theologie der Psalmen, Göttingen 1989, 219, 220.

12 H-J Kraus, Theologie der Psalmen, Neukirchen-Vluyn 1979, 141. Vergelyk ook R de Vaux, Ancient Israel: Its Life and Institutions, London 1968, 103.

13 Brown \& Levinson, $a$ w, 12-13.

14 Spieckermann, $a w, 219$.

15 Brown \& Levinson, $a w, 130$.

16 Perelman \& Olbrechts-Tyteca, $a w, 362-371$. Vergelyk ook vers 10-12 waar hierdie Judese koning die konings van die aarde onderrig.

17 Die teksverandering wat $\mathrm{H} \mathrm{J}$ Kraus, Psalmen $i$. Teilband, Neukirchen-Vluyn

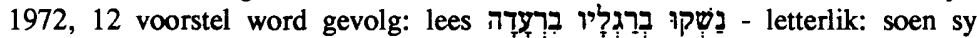
(Jahwe se) voete met bewing. Die soen van Jahwe se voete is 'n teken van dienswillige onderwerping (Jes 49:23) - Kraus, $a$ w, 1972, 20.

18 Negatiewe beleefdheid "is redressive action addressed to the addressee's negative face: his want to have his freedom of action unhindered and his attention unimpeded", aldus Brown \& Levinson, $a w, 134$.

19 Brown \& Levinson, $a w, 76,77,100,135$.

20 Vergelyk Brown \& Levinson, $a w, 76,77$ vir die voordele wat hierdie direkte negatiewe beleefdheidstrategieë inhou.

21 Perelman \& Olbrechts-Tyteca, $a w, 19$ se definisie van 'n gehoor is "the ensemble of those whom the speaker wishes to influence by his argumentation".

22 Psalm 2 is nie 'n tipiese gebed wat tot Jahwe gerig word nie. As kultiese psalm sou dit later die funksie gekry het van 'n psalm wat deur die kultiese gemeenskap hardop in die openbaar geresiteer of gebid is. 
Volgens M J Medhurst, "The Politics of Prayer: A Case Study in Configurational Interpretation", in: T W Benson (ed), American Rhetoric: Context and Criticism, Southern Illinois University 1989, 284, 287, het sulke gebede vir die gehoor die funksie van retoriese legitimering van staatsmites, byvoorbeeld dat die leier deur God geseën is en dat die volk God se volk is.

T W Benson, "Rhetoric as a Way of Being", in: T W Benson (ed), American Rhetoric: Context and Criticism, Southern Illinois University 1989, 320.

25 Spieckermann, $a w, 217$.

26 H-J Kraus, $a w, 1979,139-150$.

27 J N Vorster, The rhetorical situation of the letter to the Romans. An interactional approach, DD dissertation, Pretoria 1991, 30-31.

28 Medhurst, $a w, 267-292$.

29 Medhurst, $a w, 270$.

30 Medhurst, $a w, 286$.

31 Medhurst, $a w, 287$.

32 L F Bitzer, The rhetorical situation, Philosophy and Rhetoric 1(1968), 1-14.

33 Kraus, $a w, 1979,141$.

34 D F O'Kennedy, Prayer: An integral part of the Old Testament, Scriptura 59 (1996), 427.

35 Kraus, $a w, 1979,139$.

36 De Vaux, $a w, 102-107$.

37 Kraus, $a w, 1979,142$.

38 Vergelyk P J Nel, The theology of the Royal Psalms, OTE 11/1 (1998), 73.

39 G A Andersen, "The praise of God as cultic event", in: G A Andersen \& S M Olyan (eds), Priesthood and cult in Ancient Israel, Sheffield 1991, 428.

40 Die moontlikheid kan nie uitgesluit word dat daar diplomate van ander lande tydens die inhuldigingseremonie aanwesig sou wees nie, alhoewel hulle waarskynlik net die rituele in die paleis sou kon waarneem en aanhoor.

41 Vergelyk byvoorbeeld Psalms 110:5-6; 89:22-25.

42 Vergelyk veral verse 6 en 10-12. Kraus, $a w, 1979,94-103$, bespreek in detail die verskillende aspekte van die Sionsteologie.

43 Kraus, $a w, 1972,15$.

$44 \mathrm{Nel}, a w, 72$.

45 Teenoor de Vaux, $a w, 109$ wat van mening is dat die woorde van die psalmdigter nie buite die uitdrukkings van hofetiket gaan of meer is as die idees wat Israel self oor hul koning gehad het nie. Volgens de Vaux se siening, is die koningsbeskouing van Juda dus reeds gevestig, terwyl hier geargumenteer word dat die skepping van hierdie psalm nog deel van hierdie vormingsproses was. O'Kennedy, $a w, 430-431$. 